\title{
BIO ADSORBENT SERBUK KAYU NANGKA SEBAGAI PENJERAP ION Pb(II) DARI LARUTAN
}

\author{
Tintin Mutiara $^{1}$, Lucky Wahyu Nuzulia Setyaningsih ${ }^{1}$, Muh. Wahyu Syabani², \\ Khairunisa Betariani $^{1}$, Qonita Usthufiya ${ }^{1}$ \\ ${ }^{1}$ Jurusan Teknik Kimia, Fakultas Teknologi Industri, Universitas Islam Indonesia \\ ${ }^{2}$ Jurusan Teknologi Pengolahan Karet dan Plastik, Politeknik ATK Yogyakarta
}

Email: tintin.mutiara@uii.ac.id

\begin{abstract}
Abstrak
Penelitian ini dilaksanakan untuk mempelajari karakteristik bio adsorbent (penjerap) dari serbuk kayu nangka dan meneliti kemungkinannya sebagai penjerap ion logam berat dari larutan. Percobaan adsorpsi dilakukan untuk menghitung kapasitas penjerapan bio adsorbent. Penelitian ini membuktikan bahwa pH larutan mempengaruhi perilaku penjerapan, dengan menaikkan nilai pH dari 2 hingga 4, maka kapasitas penjerapan juga meningkat. $\mathrm{pH}$ optimum larutan untuk penjerapan ion $\mathrm{Pb}(\mathrm{II}) \mathrm{ke}$ dalam bio adsorbent adalah $\mathrm{pH}$ 4. Model kinetika orde dua cocok untuk menggambarkan proses penjerapan ion $\mathrm{Pb}(\mathrm{II})$ ke dalam bio adsorbent. Dari perhitungan model kinetika, diperoleh nilai kapasitas penjerapan pada kesetimbangan adalah 1,91 mg/g. Hasil analisa FTIR menunjukkan bahwa ikatan $\mathrm{C}-\mathrm{H}$, gugus karbonil $-\mathrm{C}=\mathrm{O}$ dan gugus nitril $-\mathrm{C} \equiv N$ memberikan kontribusi pada pengikatan ion $\mathrm{Pb}(\mathrm{II})$ di permukaan bio adsorbent.
\end{abstract}

Kata Kunci: Adsorbent, Kayu Nangka, Pb(II), Logam Berat, Serbuk Kayu

\begin{abstract}
This work was conducted to study the characteristics of bio adsorbent of untreated jackfruit wood sawdust and to investigate its possibility as an adsorbent of heavy metals from aqueous solutions. Adsorption experiments were conducted to determine the adsorption capacity of bio adsorbent. This study proved that $\mathrm{pH}$ solutions affected on adsorption behaviour, increasing the $\mathrm{pH}$ from 2 to 4 , also followed by the increase of adsorption capacity of bio adsorbent. The optimum $\mathrm{pH}$ solution for the adsorption of $\mathrm{Pb}(\mathrm{II})$ ions onto the bio adsorbent was $\mathrm{pH}$ 4. Second-order kinetics model was perfectly illustrated the adsorption process of Pb(II) ions onto bio adsorbent. From the calculation based on kinetics model, the value of the adsorption capacity of bio adsorbent at equilibrium was $1,91 \mathrm{mg} / \mathrm{g}$. FTIR spectra indicated that $\mathrm{C}-\mathrm{H}$ bond, carbonyl group $-\mathrm{C}=\mathrm{O}$ and nitrile group $-C \equiv N$ had a significant role in $\mathrm{Pb}(\mathrm{II})$ binding to bio adsorbent surface.
\end{abstract}

Keywords: Adsorbent, Heavy Metal, Jackfruit Wood, Pb(II), Sawdust

\section{PENDAHULUAN}

Logam berat adalah logam yang memiliki berat jenis lebih dari $5 \mathrm{~g} / \mathrm{cm}^{3}$ seperti arsenik, kadmium, kromium, tembaga, timbal, merkuri, nikel dan seng mampu mencemari air (Kobielska et al., 2018). Logam tersebut adalah komponen yang tidak dapat diuraikan oleh lingkungan dan cenderung untuk terakumulasi di dalam organisme yang pada akhirnya menimbulkan berbagai macam gangguan dan penyakit (Manzoor et al., 2013). Logam berat sebenarnya dibutuhkan pada proses industri namun pembuangan limbahnya kadang masih 
mengandung sejumlah tertentu logam berat yang mampu menjadi ancaman bagi kesehatan manusia dan lingkungan.

Sejumlah metode telah diaplikasikan untuk menghilangkan logam berat dari larutan, meliputi metode presipitasi (Fan et al., 2017), proses menggunakan membran (Zhaoa et al., 2018; Martin et al., 2018; Feng et al., 2018), adsorpsi (Zare et al., 2018), ion exchange (Tavakoli et al., 2017), dan lain-lain. Namun, beberapa dari metode tersebut tidak begitu efektif, mahal dan membutuhkan input energi yang besar. Oleh karena itu, kajian untuk menemukan proses baru yang lebih efisien dan murah untuk penghilangan logam berat dari limbah cair masih diperlukan.

Adsorpsi telah terbukti sebagai metode yang tepat untuk pengolahan air. Pada umumnya, air limbah mengandung logam berat dengan konsentrasi yang rendah dan adsorpsi telah terbukti mampu mengolah limbah logam berat dengan konsentrasi yang sangat rendah hingga $1 \mathrm{mg} / \mathrm{L}$ (Tripathi dan Ranjan, 2015). Disamping itu, proses adsorpsi membutuhkan biaya yang lebih rendah, desainnya sederhana dan mudah dioperasikan (Jusoha et al., 2007).

Penelitian terbaru mengenai potensi serbuk kayu pada proses penghilangan logam berat dari larutan, diantaranya dilakukan oleh Salazar-Rabago dan Leyva (2016) meneliti mengenai proses adsorpsi ion $\mathrm{Pb}(\mathrm{II})$ pada serbuk kayu pinus putih yang telah dimodifikasi dengan asam. Feng dan Zhang (2013) meneliti kemampuan residu Chinese ephedra dalam penghilangan ion $\mathrm{Pb}$ (II) dari larutan. Bozic et al., (2013) mempelajari kinetika, mekanisme dan proses kesetimbangan adsorpsi ion logam berat oleh serbuk kayu Beech. Selain itu, ekstraksi logam berharga dari limbah industri menggunakan serbuk pinus yang dimodifikasi dengan gugus thiourea dilakukan oleh Losev et al., (2018).

Pada penelitian yang telah dilakukan sebelumnya, terbukti bahwa serbuk kayu nangka alami memiliki kapasitas penjerapan 30\% lebih besar bila dibandingkan dengan serbuk kayu nangka yang dimodifikasi dengan asam asetat, pada konsentrasi ion logam mula-mula 24 ppm (Mutiara et al., 2018). Pada penelitian ini dilakukan percobaan adsorpsi pada serbuk kayu nangka tanpa modifikasi kimia untuk mengetahui kinetika penjerapan ion $\mathrm{Pb}(\mathrm{II})$, pengaruh kecepatan putar dan $\mathrm{pH}$ terhadap kapasitas penjerapan. 


\section{METODE PENELITIAN}

\section{Bahan}

Serbuk kayu nangka yang digunakan pada penelitian ini diperoleh dari industri penggergajian kayu di daerah Sleman, Yogyakarta. Bahan kimia yang digunakan untuk membuat limbah sintetis adalah $\mathrm{Pb}\left(\mathrm{NO}_{3}\right)_{2}$ dan semua larutan dibuat dengan menggunakan air distilasi sebagai pelarut, sedangkan $\mathrm{pH}$ larutan dikendalikan menggunakan $\mathrm{NaOH}$ dan $\mathrm{HCl}$.

\section{Persiapan Bahan Baku}

Serbuk kayu nangka yang merupakan limbah industri penggergajian, pertama-tama dihaluskan kembali menggunakan blender. Setelah serbuk menjadi lebih halus, serbuk di cuci menggunakan air distilasi untuk memastikan serbuk terbebas dari kotoran. Setelah ditiriskan, serbuk dikeringkan di dalam oven selama 24 jam pada suhu $80^{\circ} \mathrm{C}$. Setelah kering, kemudian serbuk diayak menggunakan saringan 80 mesh untuk mendapatkan serbuk dengan ukuran yang seragam.

\section{Analisa penjerapan ion $\mathrm{Pb}(\mathrm{II})$}

Pengaruh pH larutan terhadap kapasitas penjerapan.

Serbuk kayu nangka seberat 0,5 gram dicampur dengan $100 \mathrm{ml}$ larutan $\mathrm{Pb}$ (II) dengan konsentrasi dan $\mathrm{pH}$ yang telah ditentukan yaitu 2, 3, 4, 5, dan 6. Campuran diaduk dengan kecepatan $250 \mathrm{rpm}$ menggunakan magnetic stirrer selama 1 jam kemudian didiamkan 24 jam. Sampel diambil untuk dianalisa konsentrasinya menggunakan Atomic Absorption Spectroscopy (AAS).

Untuk menghitung jumlah ion $\mathrm{Pb}(\mathrm{II})$ yang terjerap di dalam serbuk kayu nangka, digunakan persamaan berikut:

$q_{e}=\frac{\left(c_{0}-c_{e}\right) v}{w}$

Efisiensi penjerapan atau percent removal $(\mathrm{R} \%)$ dihitung menggunakan persamaan berikut:

$\mathrm{R} \%=\frac{\left(\mathrm{c}_{0}-\mathrm{c}_{\mathrm{e}}\right)}{\mathrm{c}_{\mathrm{o}}} \times 100 \%$

dimana kapasitas penjerapan $\mathrm{q}_{\mathrm{e}}(\mathrm{mg} / \mathrm{g})$ adalah banyaknya ion $\mathrm{Pb}(\mathrm{II})$ yang terjerap pada tiap gram adsorbent pada kesetimbangan, $\mathrm{c}_{\mathrm{o}}$ dan $\mathrm{c}_{\mathrm{e}}(\mathrm{mg} / \mathrm{l})$ adalah konsentrasi larutan $\mathrm{Pb}(\mathrm{II})$ mulamula dan pada kesetimbangan. V (liter) adalah volume larutan $\mathrm{Pb}(\mathrm{II})$ dan $\mathrm{W}$ (g) adalah massa adsorbent. 
Kinetika penjerapan ion $\mathrm{Pb}(\mathrm{II})$ ke dalam bio adsorbent serbuk kayu nangka.

Serbuk kayu nangka seberat 2,5 gram direndam dalam 500 ml larutan $\mathrm{Pb}(\mathrm{II})$ dengan konsentrasi dan $\mathrm{pH}$ yang telah ditentukan. Campuran diaduk dengan kecepatan $250 \mathrm{rpm}$. Sampel diambil pada tiap waktu yang ditentukan, kemudian konsentrasinya dianalisa menggunakan Atomic Absorption Spectroscopy (AAS).

Kinetika penjerapan ion $\mathrm{Pb}(\mathrm{II})$ dianalisa menggunakan model kinetika Lagergren orde satu dan orde dua. Model kinetika Lagergren orde satu adalah sebagai berikut:

$\frac{\mathrm{d} \mathrm{q}_{\mathrm{t}}}{\mathrm{dt}}=\mathrm{k}_{1}\left(\mathrm{q}_{\mathrm{e}}-\mathrm{q}_{\mathrm{t}}\right)$

Dengan kondisi batas, saat $\mathrm{t}=0$ maka $\mathrm{qt}=0$ dan saat $\mathrm{t}=\mathrm{t}$ maka $\mathrm{qt}=\mathrm{qt}$, Persamaan (3) menjadi,

$\ln \left(\mathrm{q}_{\mathrm{e}}-\mathrm{q}_{\mathrm{t}}\right)=\ln \mathrm{q}_{\mathrm{e}}-\mathrm{k}_{\mathrm{1}} \mathrm{t}$

Dimana qt (mg/g) adalah banyaknya ion logam terjerap saat waktu $\mathrm{t}$ (menit) ; $\mathrm{k}_{1}$ adalah konstanta kecepatan (1/menit) ; qe (mg/g) adalah banyaknya ion logam terjerap pada kesetimbangan. Konstanta kecepatan $\mathrm{k}_{1}$ dapat ditentukan dengan memplotkan nilai $\ln (\mathrm{qe}-\mathrm{qt})$ terhadap nilai t.

Persamaan Lagergren orde dua adalah:

$\frac{\mathrm{dq}_{\mathrm{t}}}{\mathrm{dt}}=\mathrm{k}_{2}\left(\mathrm{q}_{\mathrm{e}}-\mathrm{q}_{\mathrm{t}}\right)^{2}$

Dengan kondisi batas jika $\mathrm{t}=0$ maka $\mathrm{q}_{\mathrm{t}}=0$ dan jika $\mathrm{t}=\mathrm{t}$ maka $\mathrm{q}_{\mathrm{t}}=\mathrm{q}_{\mathrm{t}}$. Persamaan 5 menjadi:

$\frac{t}{q_{t}}=\frac{1}{k_{z} q_{g}^{2}}+\frac{1}{q_{e}} t$

Dimana $k_{2}$ (g/mg.min) adalah konstanta kecepatan persamaan orde dua. Nilai $\mathrm{k}_{2}$ dan $\mathrm{q}_{\mathrm{e}}$ diperoleh dari slope dan intercept grafik $\mathrm{t} / \mathrm{q}_{\mathrm{t}}$ terhadap $\mathrm{t}$.

\section{Karakterisasi Serbuk Kayu Nangka}

Gugus fungsional diidentifikasi menggunakan Fourier Transform Infra-Red (FTIR) spectroscopy. Spektrum FTIR dari serbuk kayu nangka dicatat pada kisaran panjang gelombang 4000 hingga $400 \mathrm{~cm}^{-1}$ dengan Shimadzu IR Prestige 21 Fourier Transform Infrared Spectroscopy. Spektrum FTIR serbuk kayu nangka sebelum dan sesudah proses penjerapan dibandingkan, untuk mengetahui gugus fungsional yang berhubungan dengan proses penjerapan ion $\mathrm{Pb}(\mathrm{II})$ ke dalam serbuk kayu nangka. 


\section{HASIL DAN PEMBAHASAN}

\section{Pengaruh pH terhadap kapasitas penjerapan}

Gambar 1 menunjukkan pengaruh $\mathrm{pH}$ terhadap kapasitas penjerapan bio adsorbent serbuk kayu nangka. pH yang ditentukan pada penelitian ini adalah 2, 3, 4, 5 dan 6. Kapasitas penjerapan mengalami peningkatan seiring peningkatan nilai $\mathrm{pH}$ pada larutan dengan $\mathrm{pH} 2$ hingga 4. Pada larutan asam kapasitas penjerapan menurun karena pada satu situs aktif yang sama di permukaan serbuk kayu dimana pertukaran ion dapat terjadi, terdapat persaingan antara ion logam dengan proton $\mathrm{H}^{+}$(Bozic et al., 2013). Pada $\mathrm{pH}$ yang lebih tinggi konsentrasi ion $\mathrm{H}^{+}$lebih rendah dan situs aktif mampu untuk melakukan pertukaran alkali dan alkalin dari adsorbent dengan ion logam berat dari larutan (Volesky dan Holan, 1995).

Namun, kemampuan penjerapan mulai menurun saat larutan memiliki pH 5 hingga 6. Hal ini terjadi karena pada $\mathrm{pH}$ di atas 5, diketahui di dalam larutan terjadi hidrolisis ion $\mathrm{Pb}$ (II) dan terbentuk endapan tak larut timbal hidroksida (Park et al., 1999) yang mempengaruhi kapasitas penjerapan adsorbent. Dari percobaan diketahui bahwa $\mathrm{pH}$ maksimum untuk penjerapan ion $\mathrm{Pb}(\mathrm{II})$ menggunakan serbuk kayu nangka adalah $\mathrm{pH} 4$, dengan nilai percent removal (R\%) 93,7\%. Jika dibandingkan dengan hasil penelitian Meena et al. (2008) dan Feng dan Zhang (2013) dengan percent removal (R\%) pada pH 4 masing-masing kurang dari $80 \%$, hasil penelitian ini menunjukkan bahwa serbuk kayu nangka menunjukkan hasil yang sangat baik dalam menghilangkan kandungan ion $\mathrm{Pb}(\mathrm{II})$ dari larutan.

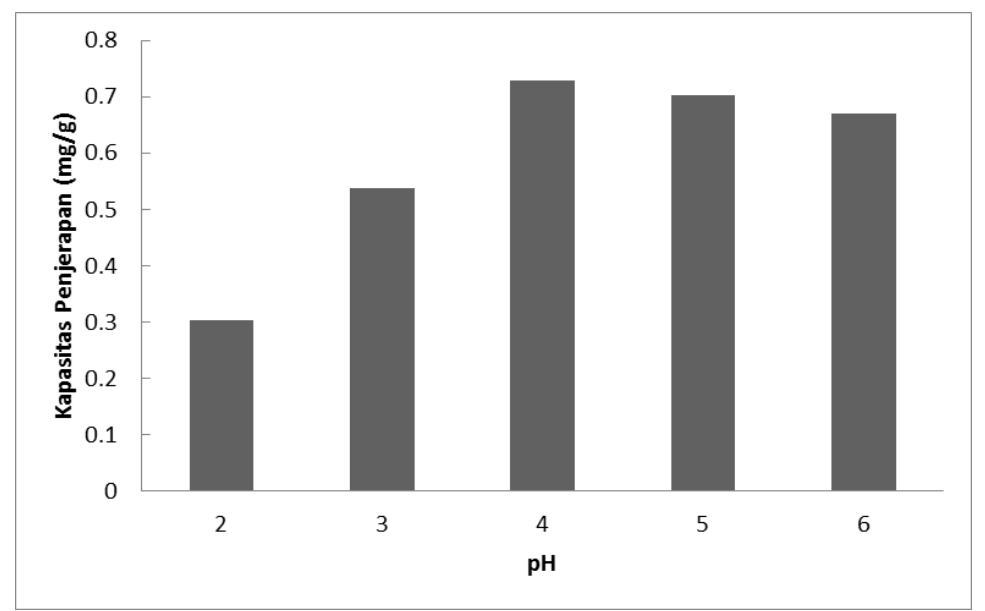

Gambar 1. Pengaruh $\mathrm{pH}$ terhadap kapasitas penjerapan ion $\mathrm{Pb}(\mathrm{II})$ ke bio adsorbent serbuk kayu nangka. 


\section{Kinetika penjerapan ion $\mathrm{Pb}(\mathrm{II})$}

Tinjauan kinetika penjerapan menjelaskan kecepatan pengambilan zat terlarut dan membuktikan pengendali kecepatan pengambilan tersebut pada batas muka larutan-padatan, termasuk proses difusi. Mekanisme penjerapan tergantung pada karakter fisika dan kimia adsorbent dan proses transfer masa (Metcalf dan Eddy, 2003). Kinetika penjerapan ion $\mathrm{Pb}(\mathrm{II})$ pada penelitian ini dimodelkan dengan model kinetika Lagergren orde satu dan orde dua, dengan hasil seperti tersaji pada Gambar 2 dan Tabel 1.

Berdasarkan Tabel 1 dan Gambar 2 dapat dilihat bahwa model kinetika orde dua dapat mewakili peristiwa penjerapan ion $\mathrm{Pb}(\mathrm{II})$ ke dalam bio adsorbent serbuk kayu nangka. Model orde dua didasarkan pada asumsi bahwa batasan kecepatan dimungkinkan oleh sorpsi kimia yang melibatkan gaya valensi melalui penggunaan bersama atau pertukaran ion antara ion $\mathrm{Pb}$ (II) dengan adsorbent (Feng dan Zhang, 2013).

Dari model kinetika orde dua dapat diketahui nilai kapasitas penjerapan pada kesetimbangan yaitu $1,91 \mathrm{mg} / \mathrm{g}$ dan waktu optimum penjerapan adalah 360 menit. Setelah itu kapasitas penjerapan masih mengalami peningkatan namun nilainya sangat kecil yaitu kurang dari $10^{-3}$ $\mathrm{mg} / \mathrm{g}$.

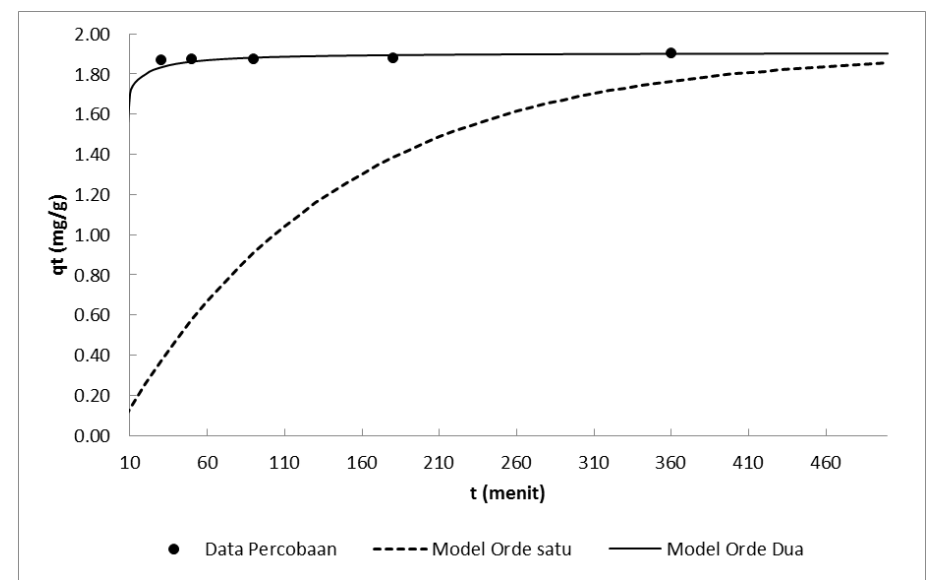

Gambar 2. Model kinetika Lagergren orde satu dan orde dua penjerapan ion $\mathrm{Pb}(\mathrm{II})$ dalam serbuk kayu nangka. Massa serbuk kayu 2,5 gram, konsentrasi ion Pb(II) mula-mula 10,4 $\mathrm{mg} / \mathrm{L}$, dan volume larutan $500 \mathrm{~mL}$. 
Tabel 1. Nilai parameter model kinetika Lagergren orde satu dan orde dua penjerapan ion $\mathrm{Pb}$ (II) dalam serbuk kayu nangka

\begin{tabular}{cccccc}
\hline Bio adsorbent & $\mathrm{q}_{\mathrm{e}}$ & \multicolumn{2}{c}{ Model orde satu } & \multicolumn{2}{c}{ Model orde dua } \\
& $(\mathrm{mg} / \mathrm{g})$ & $\mathrm{k}_{1}(1 / \mathrm{min})$ & $\mathrm{SSE}$ & $\mathrm{k}_{2}(\mathrm{~g} / \mathrm{mg} . \mathrm{min})$ & $\mathrm{SSE}$ \\
\hline $\begin{array}{c}\text { Serbuk kayu } \\
\text { nangka }\end{array}$ & 1,91 & 0,0072 & 5,1413 & 0,435 & 0,0033 \\
\hline
\end{tabular}

\section{Spektrum FTIR}

Spektrum infra merah serbuk kayu nangka alami dengan serbuk kayu nangka dengan kandungan ion $\mathrm{Pb}(\mathrm{II})$ diperoleh dengan menggunakan Shimadzu IR Prestige 21 Fourier Transform Infrared Spectroscopy. Spektroskopi infra merah adalah salah satu teknik spektroskopi yang umum digunakan untuk komponen organik dan anorganik. Gambar 3 menunjukkan sejumlah puncak absorpsi yang menandakan keberadaan gugus-gugus fungsional yang dimiliki oleh serbuk kayu nangka. Pada Gambar 3 dibandingkan antara puncak absorpsi yang dimiliki oleh serbuk kayu nangka sebelum dengan serbuk kayu nangka setelah proses penjerapan ion $\mathrm{Pb}(\mathrm{II})$.

Analisa FTIR menunjukkan puncak pada panjang gelombang $3431 \mathrm{~cm}^{-1}$ mengindikasikan keberadaan gugus hidroksil $-\mathrm{OH}$ dan amina -NH. Puncak pada $2362 \mathrm{~cm}^{-1}$ menunjukkan adanya gugus nitril $-\mathrm{C} \equiv \mathrm{N}$. Puncak di $1636 \mathrm{~cm}^{-1}$ mewakili gugus $-\mathrm{C}=\mathrm{O}$ yang mungkin berasal dari gugus karboksil atau gugus ester. Puncak pada $1510 \mathrm{~cm}^{-1}$ mengindikasikan keberadaan gugus karbonil $-\mathrm{C}=\mathrm{O}$, puncak pada $1426 \mathrm{~cm}^{-1}$ menunjukan adanya gugus $\mathrm{CH}_{3}$, puncak di $1380 \mathrm{~cm}^{-1}$ menandakan vibrasi $\mathrm{NO}_{2}$, puncak pada $1256 \mathrm{~cm}^{-1}$ menandakan keberadaan $\mathrm{SO}_{3}$, puncak pada $1058 \mathrm{~cm}^{-1}$ menunjukkan adanya C-O dari polisakarida, dan puncak pada 517 $\mathrm{cm}^{-1}$ mengindikasikan gugus $-\mathrm{CN}$.

Terdapat pergeseran puncak antara serbuk kayu nangka alami dan serbuk kayu nangka yang mengandung ion $\mathrm{Pb}(\mathrm{II})$, menandakan peran gugus-gugus fungsi dalam pengikatan ion $\mathrm{Pb}(\mathrm{II})$ di permukaan serbuk kayu. Munculnya puncak pada panjang gelombang $2900 \mathrm{~cm}^{-1}$ gugus fungsional $\mathrm{C}-\mathrm{H}$ dari golongan metil dan metilena dan muncul puncak pada $1735 \mathrm{~cm}^{-1}$ mengindikasikan adanya $-\mathrm{C}=\mathrm{O}$ dari gugus karboksilat. Selain itu, intensitas puncak gelombang mengalami peningkatan setelah proses penjerapan yaitu pada panjang gelombang 2360 dan $1510 \mathrm{~cm}^{-1}$ yang menandakan keberadaan gugus nitril $-\mathrm{C} \equiv \mathrm{N}$ dan gugus karbonil $\mathrm{C}=\mathrm{O}$. Berdasarkan analisa spektrum FTIR dapat diketahui bahwa gugus fungsional yang 
berperan pada proses penjerapan ion logam $\mathrm{Pb}(\mathrm{II})$ oleh serbuk kayu nangka adalah ikatan $\mathrm{C}-$ $\mathrm{H}$ dari golongan metil dan metilena, gugus karbonil $-\mathrm{C}=\mathrm{O}$ dan gugus nitril $-\mathrm{C} \equiv \mathrm{N}$ yang ditandai dengan kemunculan puncak baru dan peningkatan intensitas. Gugus fungsi $\mathrm{C}-\mathrm{H}$ dan $\mathrm{C}=\mathrm{O}$ umum terdapat pada material tanaman yang kaya akan selulosa (Losev et al., 2018), dan terutama gugus fungsi $\mathrm{C}=\mathrm{O}$ dan $\mathrm{CN}$ terlibat pada proses biosorpsi (Vinodhini dan Das, 2009).

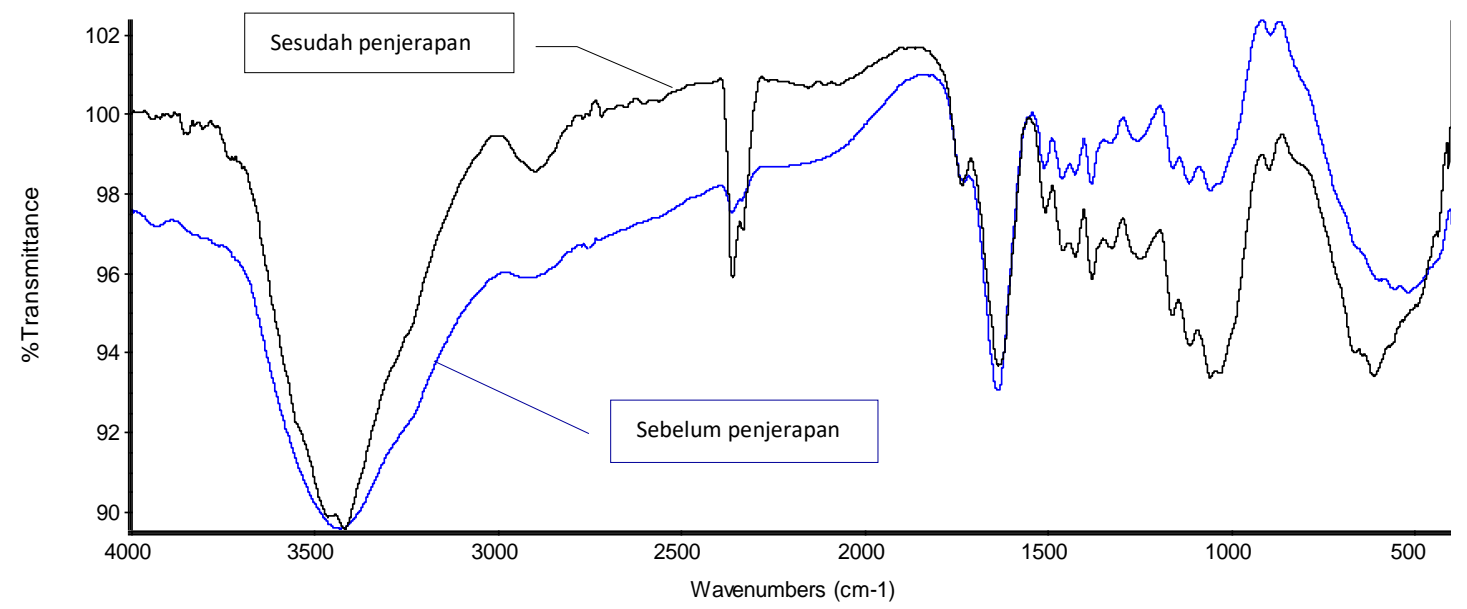

Gambar 3. Perbandingan spektrum infra merah serbuk bio adsorbent kayu nangka sebelum dan setelah proses penjerapan

\section{KESIMPULAN}

Penelitian ini membuktikan bahwa bio adsorbent dari serbuk kayu nangka dapat menjadi adsorbent yang efektif dalam menjerap ion logam $\mathrm{Pb}(\mathrm{II})$ dari larutan. Hasil penelitian menunjukkan bahwa $\mathrm{pH}$ larutan berperan penting pada penjerapan ion $\mathrm{Pb}(\mathrm{II})$, pada $\mathrm{pH} 2$ hingga 4 kapasitas penjerapan naik seiring dengan kenaikan nilai $\mathrm{pH}$, namun kemampuan penjerapan mengalami penurunan pada $\mathrm{pH}$ larutan 5 hingga 6. Kinetika penjerapan ion $\mathrm{Pb}(\mathrm{II})$ ke dalam bio adsorbent serbuk kayu nangka terwakili dengan baik oleh model kinetika orde dua dengan persamaan: $\frac{\mathrm{t}}{\mathrm{q}_{\mathrm{t}}}=\frac{1}{1,582}+\frac{1}{1,91} \mathrm{t}$, dengan nilai SSE sebesar 0,0033. Analisa FTIR dilakukan untuk mengetahui gugus fungsional yang berperan pada proses penjerapan ion $\mathrm{Pb}$ (II) oleh serbuk kayu nangka. Dari spektrum infra merah diketahui bahwa ikatan $\mathrm{C}-\mathrm{H}$ dari golongan metil dan metilena, gugus karbonil $-\mathrm{C}=\mathrm{O}$ dan gugus nitril $-\mathrm{C} \equiv \mathrm{N}$ memberikan kontribusi pada pengikatan ion $\mathrm{Pb}(\mathrm{II})$ di permukaan bio adsorbent. 


\section{DAFTAR PUSTAKA}

Bozic, D., Gorgievski, M., Stankovic, V., Strbac, N., Serbula, S., Petrovic, N., (2013), Adsorption of heavy metal ions by beech sawdust - Kinetics, mechanism and equilibrium of the process, Ecological Engineering, 58, pp. 202-206.

Fan, Hong-Lei, Zhou, Shao-Feng, Jiao, Wei-Zhou, Qi Gui-Sheng, Liu, You-Zhi, (2017), Removal of heavy metal ions by magnetic chitosan nanoparticles prepared continuously via high-gravity reactive precipitation method, Carbohydrate Polymers, 174, pp. 11921200.

Feng, Q., Wu, D., Zhao, Y., Wei, A., Wei, Q., Fong, H., (2018), Electrospun AOPAN/RC blend nanofiber membrane for efficient removal of heavy metal ions from water, Journal of Hazardous Materials, 344, pp. 819-828.

Feng, N. and Zhang, F., (2013), Untreated Chinese ephedra residue as biosorbents for the removal of $\mathrm{Pb}^{2+}$ ions from aqueous solutions, Procedia Environmental Sciences, 18, pp. 794-799.

Jusoha, A., Lam, S.S., Noraaini, A., Noor, M.J.M.M., (2007), A simulation study of the removal efficiency of granular activated carbon on cadmium and lead, Desalination, 206, pp. 9-16.

Kobielska P.A., Howarth A.J., Farha O.K., Nayak S., (2018), Metal-organic frameworks for heavy metal removal from water, Coordination Chemistry Reviews, 358, pp. 92-107.

Losev, V.N., Elsufiev, E.V., Buyko, O.V., Trofimchuk, A.K., Horda, R.V., Legenchuk, O.V., (2018), Extraction of precious metals from industrial solutions by the pine (Pinus sylvestris) sawdust-based biosorbent modified with thiourea groups, Hydrometallurgy, 176, pp. $118-128$.

Manzoor Q., Nadeem, R., Iqbal, M., Saeed, R., Ansari, T.M., (2013), Organic acids pretreatment effect on Rosa bourbonia phyto-biomass for removal of $\mathrm{Pb}$ (II) and $\mathrm{Cu}$ (II) from aqueous media, Bioresource Technology, 132, pp. 446-452.

Martin, D.M., Faccinia, M., García, M.A., Amantia, D., (2018), Highly efficient removal of heavy metal ions from polluted water using ion-selective polyacrylonitrile nanofibers, Journal of Environmental Chemical Engineering, 6(1), pp. 236-245.

Meena, A.K., Kadirvelu, K., Mishra, G.K., (2008), Adsorptive removal of heavy metals from aqueous solution by treated sawdust (Acacia arabica), Journal of Hazardous Materials, 150, pp. 604-611

Metcalf dan Eddy, 2003. Wastewater Engineering, Treatment and Reuse, fourth edition, McGraw-Hill Publishing Company Limited, New Delhi. 
Mutiara, T., Karisa, P.C., Mujahidah, I., (2018), Acid modified jackfruit wood sawdust as biosorbent for the removal of $\mathrm{Fe}(\mathrm{II})$ from aqueous solutions, MATEC Web of Conferences, 154, pp. 01019.

Park, J.Y., Jeon, C., Yoo, Y.J., (1999), Journal of Microbiology Biotechnology, 9, pp. 650.

Salazar-Rabago, J.J. and Leyva-Ramos, R., (2016), Novel biosorbent with high adsorption capacity prepared by chemical modification of white pine (Pinus durangensis) sawdust. Adsorption of $\mathrm{Pb}(\mathrm{II})$ from aqueous solutions, Journal of Environmental Management, 169 , pp. 303-312.

Tavakoli, O., Goodarzi, V., Saeb, M.R., Mahmoodi, N.M., Borja, R., (2017), Competitive Removal of Heavy Metal Ions from Squid Oil Under Isothermal Condition by CR11 Chelate Ion Exchanger, Journal of Hazardous Materials, 334, pp. 256-266.

Tripathi, A., and Ranjan, M.R., (2015), Heavy Metal Removal from Wastewater Using Low Cost Adsorbents, Journal of Bioremediation \& Biodegradation, 6, pp. 6.

Vinodhini, V. and Das, N., (2009), Mechanism of Cr (VI) Biosorption by Neem Sawdust, American-Eurasian Journal of Scientific Research, 4 (4), pp. 324-329.

Volesky, B., Holan, Z.R., (1995), Biosorption of heavy metals, Biotechnology Prog., 11, pp. $235-250$.

Zare, E.N., Motahari, A., Sillanpää, M., (2018), Nanoadsorbents based on conducting polymer nanocomposites with main focus on polyaniline and its derivatives for removal of heavy metal ions/dyes: A review, Environmental Research, 162, pp. 173-195.

Zhaoa, X. and Liu, C. (2018), Efficient removal of heavy metal ions based on the optimized dissolution-diffusion-flow forward osmosis process, Chemical Engineering Journal, 334, pp. 1128-1134. 